Tohoku J. Exp. Med., 2005, 206, 243-246

\title{
Is There a Link between Nickel Allergy and Coronary Stent Restenosis?
}

\author{
Tugrul Norgaz, Gultekin Hobikoglu, Zehra Asiran Serdar, ${ }^{1}$ Huseyin Aksu, \\ Ahmet Taha Alper, Orhan Ozer and Ahmet Narin \\ Siyami Ersek Thoracic and Cardiovascular Surgery Center, Department of \\ Cardiology, and \\ ${ }^{I}$ Haydarpasa Numune Hospital, Department of Dermatology, Istanbul, Turkey
}

\begin{abstract}
Norgaz, T., Hobikoglu, G., Serdar, Z.A., Aksu, H., Alper, A.T., Ozer, O. and NARIN, A. Is There a Link between Nickel Allergy and Coronary Stent Restenosis? Tohoku J. Exp. Med., 2005, 206 (3), 243-246 — Although many patients with coronary artery disease are being treated by coronary stents, in-stent restenosis is the major limitation of percutaneous coronary stenting procedures. Most stents are made of stainless steel, and that, allergic reactions to nickel ions released from coronary stainless-steel stents may be one of the triggering mechanisms for in-stent restenosis. We aimed to evaluate the relationship between in-stent restenosis and nickel allergy in a prospective study. For this purpose, we applied epicutaneous patch test for nickel in 43 patients who had undergone elective intracoronary stent placement for stable angina pectoris in the day following stent placement and evaluated the presence of nickel allergy. Control angiography was performed at 6 months to determine in-stent restenosis. Three (6.9\%) patients had allergic reaction to nickel and $16(37 \%)$ patients had developed in-stent restenosis. One of the 3 patients with nickel allergy had diffuse in-stent restenosis and the others not. The present study therefore does not support the proposed relationship between nickel allergy and development of in-stent restenosis in patients having stainless steel stents. Large scale studies are needed to reach a final conclusion. — coronary stenting; in-stent restenosis; metal allergy; nickel; patch test

(C) 2005 Tohoku University Medical Press
\end{abstract}

Over 1.5 million percutaneous coronary revascularisation procedures are performed annually world wide, most being intracoronary stenting. Despite enormous advances in devices, the major limitation is restenosis following intracoronary stent placement (in-stent restenosis) (Bennett et al. 2003). The mechanisms of in-stent restenosis (ISR) include an excessive fibroproliferative and inflammatory response to the arterial injury (Ross 1999). Köster et al. (2000) have supposed that al- lergic reactions to nickel and molybdenum ions released from stainless-steel coronary stents may be one of the triggering mechanisms for the development of in-stent restenosis (ISR) in a retrospective study, and they concluded that stainlesssteel stents should be avoided for patients with proven hypersensitivity to metals or with history of metal allergy. Nickel contact allergy is a common form of allergic contact dermatitis (Schnuch 2003). We aimed to evaluate the relationship be-

Received December 20, 2004; revision accepted for publication April 25, 2005.

Correspondence: Dr. Tugrul Norgaz, Kaptan Arif sokak, Dincer Apt. A blok, No: 59/11, 81061, Erenkoy, Istanbul, Turkey.

e-mail: tnorgaz@yahoo.com 
tween presence of nickel contact allergy and development of ISR in patients having stainlesssteel stents in a prospective study.

\section{Materials and Methods}

\section{Study patients}

Forty-five consecutive patients who had undergone elective intracoronary stent placement for stable angina pectoris and approved to join the study were included. Informed consent was obtained from all patients, and approval by the institution's ethic committee was taken. All patients had at least 50\% narrowing in a single native coronary artery. Patients who had prior coronary interventions, patients with acute coronary syndromes, patients having immune-suppressive diseases or taking immune-suppressive drugs were excluded.

The presence conventional risk factors for coronary artery disease (diabetes mellitus, hypertension, smoking status, hypercholesterolemia, and family history of premature coronary artery disease) were sought. Also, the history of known metal contact allergy and history of any allergic diseases of the skin (such as allergic contact dermatitis and urticaria) were asked.

\section{Stenting procedure}

Coronary angiography and coronary stenting were performed via a femoral artery approach using standard techniques. 316L stainless-steel, balloon expandable, tubular slotted stents of appropriate size were implanted after predilatation with coronary angioplasty balloons in tight lesions and directly in others. Post-dilatation with angioplasty balloons was performed if needed according to the operator's judgement. All patients were premedicated with antiplatelet drugs: $100-300 \mathrm{mg} /$ day of aspirin and $75 \mathrm{mg} /$ day of clopidogrel at least for 1 week. A total of 10,000 units of unfractioned heparin was administered at the time of procedure. All patients continued on aspirin 100-300 mg/day thereafter and clopidogrel $75 \mathrm{mg} /$ day for at least 6 months.

\section{Evaluation of nickel allergy}

To test the presence of allergic reaction to nickel, a $5 \%$ nickel sulphate solution in petrolatum (Stallerpatch, Cedex, France) was applied as a patch test by Finnchamber method to the interscapular region on the day following stent placement. The test was carried out and analysed according to the recommendations of the International Contact Dermatitis Research Group (Fregert 1981). Hypersensitivity reaction was evaluated by an experienced dermatologist after 48 hours, 72 hours, and when necessary after 96 hours. The criteria for a positive reaction were an inflammatory response with erythema, oedema, papulovesicles, or infiltration after 48 hours or 72 hours.

\section{Follow-up and detection of restenosis}

Patients were re-evaluated at the 6th month, or earlier if symptoms developed. Relapsing angina pectoris, development of acute coronary syndromes or major adverse cardiac events and repeat revascularisation were sought. Control coronary angiograpy was performed and coronary angiograms were evaluated for detection of ISR by an interventional cardiologist who was unaware of the patch test results and clinical findings of the patients. Patients who had $>50 \%$ narrowing within the limits of the stent were considered as the ISR group.

\section{Statistics}

Data are presented as mean \pm S.D. or percentage. Mann Whitney's test for numeric variables and chisquare test for non-numeric variables were performed to compare study groups. The SPSS 10.0 program for Windows was utilized for the entire statistical work-up. A $p$ value of $<0.05$ was considered to be statistically significant.

\section{RESUlts}

Two of 45 patients were lost during followup and final study group was consisted of 43 subjects ( 35 male and 8 female patients, mean age $57.27 \pm 8.75$ years). Angiography was performed $6.7 \pm 2.7$ months after the stent placement, showing that $16(37 \%)$ patients had ISR. There were no statistically significant differences between patients with ISR and those without ISR (no-ISR group) for demographic parameters and clinical risk factors (Table 1). Patch test results for nickel contact allergy were shown in Table 2. According to the patch test results, 3 patients had nickel contact allergy. One of these 3 patients (58 years old male) had diffuse ISR, which was demonstrated by coronary angiography performed at 4.1 months due to development of symptoms, whereas the other 2 patients (55 years old male and 54 years old female) had no evidence of ISR at 6th month, as judged by control angiography. 
TABLE 1. Comparison of patients with in-stent restenosis (ISR group) and without in-stent restenosis (no-ISR group) for demographic parameters and clinical risk factors of coronary artery disease

\begin{tabular}{lccc}
\hline & $\begin{array}{c}\text { ISR } \\
(n=16)\end{array}$ & $\begin{array}{c}\text { No ISR } \\
(n=27)\end{array}$ & $p$ value \\
\hline Age (years) & $55.50 \pm 10.46$ & $58.33 \pm 7.59$ & 0.212 \\
Gender: Male (\%) & $14(87.5)$ & $21(77.8)$ & 0.428 \\
$\quad$ Female (\%) & $2(12.5)$ & $6(22.2)$ & \\
Diabetes mellitus (\%) & $2(12.5)$ & $4(14.8)$ & 0.832 \\
Hypertension (\%) & $7(43.8)$ & $9(33.3)$ & 0.495 \\
Smoking (\%) & $9(59.3)$ & $14(51.5)$ & 0.780 \\
Hypercholesterolemia & $5(31.3)$ & $6(22.2)$ & 0.512 \\
Family history of CAD* (\%) & $5(31.3)$ & $7(25.9)$ & 0.707 \\
History of metal contact allergy (\%) & $1(6.3)$ & $2(7.4)$ & 0.885 \\
History of any allergic disease of skin ${ }^{* *}(\%)$ & $2(12.5)$ & $8(29.6)$ & 0.199 \\
Time to control angiography (months) & $6.93 \pm 2.49$ & $6.51 \pm 2.29$ & 0.949 \\
\hline
\end{tabular}

${ }^{*} \mathrm{CAD}$; coronary artery disease; ${ }^{* *}$ except for metal contact allergy.

TABLE 2. Comparison of patch test results for nickel in patients with in-stent restenosis (ISR group) and without in-stent restenosis (no-ISR group)

\begin{tabular}{lccc}
\hline & ISR group $(n=16)$ & No ISR group $(n=27)$ & Total $(n=43)$ \\
\hline $\begin{array}{l}\text { Positive patch test } \\
\text { reaction to nickel (\%) }\end{array}$ & $1^{*}(6.3)$ & $2^{* *}(7.4)$ & $3(6.9)$ \\
$\begin{array}{l}\text { Negative patch test } \\
\text { reaction to nickel (\%) }\end{array}$ & $15(93.7)$ & $25(92.6)$ & $40(93.1)$ \\
\hline
\end{tabular}

* 58 years old male patient with no history of metal contact allergy.

** 55 years old male and 54 years old female patients; both without history of metal contact allergy.

These 3 patients with positive patch test reaction to nickel had no history of allergic disease of skin or history of metal contact allergy. On the other hand, there were 3 patients who had reported history of metal contact allergy, but all of these patients had negative patch test reaction to nickel.

\section{Discussion}

The present study does not support the presence of a relationship between development of ISR and allergic reaction to nickel for patients carrying stainless steel stents. Most of the stents are made of $316 \mathrm{~L}$ stainless steel which has a nickel content of $12 \%$. The hypothesis assuming that one of the triggering mechanisms of ISR for stainless steel stents might be the hypersensitivity reaction against the allergen metal ions included in these stents was proposed by Köster et al. (2000). In that study, 131 patients who had undergone angiography with suspected ISR were evaluated retrospectively; epicutaneous patch tests for nickel sulphate, potassium dichromate, molybdenum chloride, and manganese oxide were applied to the patients within the 2 months following angiography. Eighty-nine cases had ISR, and 10 of 11 patients who had positive patch test results ( 7 for nickel, 4 for molybdenum) were found to have restenosis. As a result, Köster et al. (2000) have concluded that, stainless steel stents should be avoided in patients with known metal allergy or with proven hypersensitivity to metals. On the other hand, Keane et al. (2001) have criticised their study because only a group with suspected ISR was evaluated retrospectively, and 
a group of patients who has metal allergy but who did not developed restenosis lacks. In our study we have performed the patch test in the day following stent implantation and followed-up for development of ISR prospectively. The low rate of nickel contact allergy (6.9\%) in our group did not let us to define a relationship between ISR and nickel allergy, and our observation did not support the proposed relationship. Hillen et al. (2002) have published the data of 34 patients, in which 4 of them had nickel allergy, and only one of these four patients had ISR, which is in concordance with ours.

The rate of having a positive patch test result for nickel was similar in the Germany-based studies of both Köstner et al. (2000) and Hillen et al. (2002) (8\% and $11 \%$, respectively) and was higher than our group (6.9\%). There are no studies reporting the rate of nickel contact allergy in the general Turkish population, but Akasya et al. (2002) have reported a rate of $19 \%$ for hypersensitivity to nickel in a population who had undergone patch test for suspected contact dermatitis. Meanwhile, rate of nickel contact allergy in the general German population and German allergic contact dermatitis patients have been reported as approximately $20 \%$ and $40 \%$, respectively (Schnuch et al. 2003). The reasons of the difference between the rate of nickel contact allergy between German and Turkish populations is not clear and may be environmental or genetic. On the other hand, nickel contact allergy is more prevalent in young and females; so the low rate of nickel allergy in a group of coronary artery disease patients who are predominantly male and older, is not suprising.

\section{Conclusion}

The present study does not support the proposed relationship between nickel allergy and development of ISR in patients having stainless steel stents. When our observation is taken into consideration together with the observation of Hillen et al. (2002), the conclusion of Köster et al. (2000) stating that stainless steel stents should be avoided in patients with known metal allergy or with proven hypersensitivity to metals is not supported. Large scale prospective studies are needed to reach a final conclusion.

\section{References}

Akasya-Hillenbrand, E. \& Ozkaya-Bayazit, E. (2002) Patch test results in 542 patients with suspected contact dermatitis in Turkey. Contact Dermatitis, 46, 17-23.

Bennett, M.R. (2003) In-stent stenosis: Pathology and implications for the development of drug eluting stents. Heart, 89, 218-224.

Fregert, S. (1981) Manuel of Contact Dermatitis, 2nd ed., Copenhagen, Munksgaard.

Hillen, U., Haude, M., Erbel, R. \& Goos, M. (2002) Evaluation of metal allergies in patients with coronary stents. Contact Dermatitis, 47, 353-356.

Keane, F., Morris, S., Smith, H. \& Rycroft, R.J. (2001) Allergy in coronary in-stent restenosis. Lancet, 357, 1205-1206.

Köster, R., Vieluf, D., Kiehn, M., Sommerauer, M., Kahler, J., Baldus, S., Meinertz, T. \& Hamm, C.W. (2000) Nickel and molybdenum contact allergies in patients with coronary instent restenosis. Lancet, 356, 1895-1897.

Ross, R. (1999) Atherosclerosis- an inflammatory disease. $N$. Engl. J. Med., 3430, 115-126.

Schnuch, A., Geier, J., Lessmann, H. \& Uter, W. (2003) decrease in nickel sensitization in young patients- successful intervention through nickel exposure regulation? Results of IVDK, 1992-2001. Hautarzt, 54, 626-632. 